\title{
Os "latinos" viajam à Meca do Cinema"
}

\author{
Miriam Viviana Gárate²
} 13 a 17 de agosto de 2014 no Memorial de América Latina. 


\section{Resumo}

A presença de relatos que se organizam em torno do motivo da viagem a Hollywood é um dado significativo das letras latinoamericanas dos anos 1920-1930, que corre paralelo à expansão da cinematografia estadunidense. Una aventura de amor, Miss Dorothy Phillips, mi esposa, Che Ferrati, inventor e Hollywood, novela da vida real constituem exemplos a serem analisados. Para tanto, serão levados em conta os seguintes aspectos: o desvendamento das regras que vigoram nos grandes estúdios; o retrato de tipos que se consolidam por esses anos; a relação mimética das personagens com o cinema em diversos âmbitos; o vínculo afetivo espectador-estrela; o tema do dublê; a imbricação crítica cinematográfica/ficção literária; a utilização de procedimentos que tendem a conferir à escrita uma estrutura e um dinamismo cinemáticos.

\section{Palavras-chave}

Hollywood, América Latina, narrativa.

\section{Abstract}

The presence of accounts organized around the reason behind a trip to Hollywood is a significant piece of information of Latin American literature from the 1920s through the 1930s, which runs parallel the expansion of the American cinematography. Una aventura de amor (1918), Miss Dorothy Phillips, mi esposa (1919), Che Ferrati, inventor (1923) and Hollywood, novela da vida real (1932) are examples to be analyzed. With this goal, the following aspects will be considered: the unraveling of the rules that are in place in major studios; the portrait of "types" that are consolidated during these years; the mimetic relationship of the characters with cinema in a variety of frameworks; the spectator-star emotional bond; the theme of the stunt-double; the critical imbrications between cinematography and literary fiction; the use of procedures tending towards giving the writing a cinematic structure and dynamism.

\section{Keywords}

Hollywood, Latin America, narrative. 
A presença de relatos que tematizam a viagem a Hollywood é um dado significativo das letras latinoamericanas dos anos 1920-1930. Una aventura de amor (1918), publicado no Chile sob o pseudônimo de Boy; Miss Dorothy Phillips, mi esposa (1919), do uruguaio Horacio Quiroga; Che Ferrati, inventor (1923), do mexicano Carlos Noriega Hope; e Hollywood, novela da vida real (1932), do brasileiro Olympio Guilherme, estruturam-se ao redor desse motivo. Talvez não seja coincidência que o happy end se torne mais e mais unhappy à medida que a viagem deixa de ser um sonho, ou que o par pobre-diabo sedutor/estrela seduzida ceda lugar à proliferação de figurantes, às voltas com um cotidiano cada vez mais difícil, trajetória disfórica que gostaria de acompanhar. Características menos vinculadas à peripécia geram conexões de outra ordem entre os componentes do corpus: a imbricação crítica cinematográfica/ficção literária é uma delas; a utilização de procedimentos tendentes a conferir à escrita uma estrutura cinemática é outra. A seguir, propõe-se uma leitura desse conjunto textual.

\section{Viagens vividas (sonhadas) na escuridão}

Como é sabido, os fatores envolvidos na situação cinema aliam-se ao efeito de presença da linguagem cinematográfica transparente (XAVIER, 1984) para propiciar uma experiência que se constitui como cancelamento provisório da realidade imediata e como deslocamento (viagem) a uma realidade paralela. Isso levou à postulação, muito cedo, de uma analogia com o par vigília/sonho: abolindo temporariamente a dimensão diurna, a sala escura oferece ao espectador uma tela na qual se projetam (e ele projeta) fantasias compensatórias, em uma espécie de sonho acordado. Esse dispositivo é delineado em várias crônicas das primeiras décadas do século $X X$, que traçam o perfil de um público-alvo constituído por moças suburbanas ou funcionários de baixo escalão. Trata-se de uma tipologia que medra na literatura veiculada por publicações populares, reencenando na letra o jogo identificatório/projetivo proposto pela tela. Guillermo Grant, narrador-protagonista de Miss Dorothy Phillips, oferece um retrato eloquente do pobre-diabo cinéfilo: 
Eu pertenço ao grupo dos pobres-diabos que saem do cinematógrafo noite após noite apaixonados por uma estrela [...] tenho trinta e um anos, sou alto, magro e moreno - como quadra, para efeitos de exportação, a um sulamericano. Vivo em uma situação modesta e vou levando a vida sem reclamar [...] Nas fases ruins, cheguei a viver duas vidas distintas: uma durante o dia, no escritório, a outra, de noite, que se prolonga até o amanhecer. Porque eu sonho, sonho sempre (QUIROGA,1996, p.436-8)3.

Os parágrafos citados instauram a ambiguidade que permeia o relato e que somente se dirime no derradeiro desenlace, já que a rigor o conto põe em cena dois finais sucessivos. De um lado, a história é conduzida até o último momento como se pertencesse à dimensão diurna. Segundo essa convenção de leitura, que o texto convida a assumir até o epílogo, Grant queima suas magras economias, vai a Hollywood, simula ser um abastado cinéfilo, conquista Dorothy Phillips, revela mais tarde sua verdadeira condição, é perdoado pela estrela e, às vésperas do casamento, cogita escrever um roteiro baseando-se na aventura vivida. De outro lado, o epílogo que sucede a esse happy end declara a condição onírica da história obrigando a sua redefinição retrospectiva: ao invés de aventura real, peripécia sonhada; ao invés de roteiro de um filme futuro, matéria de um escrito já lido.

\footnotetext{
Mas, isto é um sonho!Tim-tim por tim-tim, como acabo de contá-lo, foi sonhado... Não sobra outra coisa para o resto de meus dias que uma profunda emoção e o pobre paliativo de remeter a Dolly o relato, com esta dedicatória: "À senhora Dorothy Phillips, rogando-Ihe perdoe as impertinências deste sonho, muito doce para o autor" (QUIROGA, 1996, p. 463)4.
}

Tradução minha. No original: "Yo pertenezco al grupo de los pobres diablos que salen noche a noche del cinematógrafo enamorados de una estrella. Me Ilamo Guillermo Grant, tengo treinta y un años, soy alto, delgado y trigueño - como cuadra, a efectos de la exportación a un americano del sur-. Estoy apenas en regular posición, y gozo de buena salud [...] En ciertos malos momentos he llegado a vivir dos vidas distintas: una durante el día, en mi oficina y el ambiente normal de Buenos Aires, y la otra de noche, que se prolonga hasta el amanecer. Porque sueño, sueño siempre". haré en seguida- con esta dedicatoria: "A la señora Dorothy Phillips, rogándole perdone las impertinencias de este sueño, muy dulce para el autor". 
Duplicidade análoga organiza Una aventura de amor (1918), publicado meses antes no Chile. Nesse caso, porém, a frase que desenha a situação inicial explicita simultaneamente o desejo do narrador por Carmel Myers e o teor escrito da confissão, abertamente endereçada ao público: "Começarei fazendo uma confissão a minhas leitoras: estou apaixonado por Carmel Myers" (BOY, 2011, p.380, tradução minha). Na origem do desejo, previsivelmente, a estreia de um filme; na sequência, a perseguição deflagrada por um espetáculo que faculta - e insta - repetir a satisfação: "a noite seguinte, e todas as noites em que a fita foi projetada, fui vê-la de novo", "depois a fita foi a Valparaíso", "eu fui atrás dela" (BOY, 2011, p. 380, tradução minha). A perseguição a Carmel Myers feita de luz e sombra é trocada de imediato pela viagem a Hollywood e pela sedução da estrela de carne e osso, desfecho redimensionado mais uma vez pelo último enunciado: "E, para concluir, devo fazer outra confissão a minhas leitoras: tudo o que contei foi sonhado em uma noite, depois de assistir a As sereias do mar" (BOY, 2011, p. 384, tradução minha).

Talvez não seja arbitrário vincular o duplo regime que molda a estrutura de ambos os contos ao progressivo "aburguesamento" do imaginário cinematográfico apontado por Edgard Morin (1989), fenômeno solidário, por sua vez, do avanço do psicologismo e do happy end na produção fílmica dos anos 1920-19305. De fato, o par regime diurno/regime onírico pode ser entendido como uma tentativa de satisfazer a demanda de "realismo" pelo viés psicológico que representa

Em relação a esse processo, o teórico sustenta: "Espetáculo plebeu em sua origem, o cinema se tinha apropriado dos temas do folhetim popular e do melodrama, nos quais se encontram em estado quase fantástico os arquétipos originais do imaginário: acasos providenciais, a magia do duplo, aventuras extraordinárias [...] O realismo, o psicologismo, o happy end e o humor revelam precisamente a transformação burguesa desse imaginário. As projeções-identificações que caracterizam a personalidade no estágio burguês tendem a aproximar o imaginário e o real, que procuram alimentar-se um do outro. O imaginário burguês aproxima-se do real ao multiplicar os sinais de verossimilhança e credibilidade. Atenua as estruturas melodramáticas para substituí-las por intrigas que se esforçam por ser plausíveis. Daí o que se chama de "realismo". Os componentes do realismo já não são o acaso, a "possessão" do herói por uma força oculta, mas as motivações psicológicas. O mesmo movimento que aproxima o imaginário do real aproxima o real do imaginário. Em outras palavras: a vida da alma se amplia, se enriquece, se hipertrofia mesmo, no interior da individualidade burguesa. O amor, fenômeno da alma que mistura de maneira mais íntima nossas projeçõesidentificações imaginárias e nossa vida real, ganha mais importância. É dentro desse quadro que se desenvolve o romantismo burguês (MORIN,1989, p.11). 
o estado de dormência, sem renunciar às reviravoltas "fantásticas" de uma fase precedente caracterizada pelo predomínio de aventuras extraordinárias. A ambivalência do narrado não denega o cotidiano ingrato. Convida a uma satisfação ilusória (e simultaneamente a desvenda), mediante a representação de uma experiência familiar e a atualização de um motivo antiquíssimo: o da dialética sonho/despertar.

Convém voltar ao conto de Quiroga e às digressões iniciais feitas pelo pobre-diabo, "alto, delgado e moreno", no qual é fácil identificar um tipo cinematográfico prestes a cristalizar-se: o latino. Alternando com os parágrafos citados, Grant intercala reflexões muito próximas às desenvolvidas pelos pioneiros da teoria do cinema e à produção crítico-ensaística do próprio Quiroga. Desfilam diante do leitor considerações sobre a relação olhar/expressividade/ fotogenia ou sobre o vínculo entre desejo erótico/tempo de exposição do objeto/ proximidade ilusória da imagem projetada. Pontuando essas observações gerais, parênteses autobiográficos modulam as mesmas questões no plano da experiência vivida pelo protagonista, levando-o à determinação de casar com uma estrela de cinema. A partir de então, os desdobramentos da peripécia podem ser lidos como as etapas de pré-produção e de rodagem de um filme. A escolha da futura esposa dentre quatro possíveis (Miriam Cooper, Dorothy Phillips, Brownie Vernon, Grace Cunard) é um sucedâneo do casting feminino, ao qual se segue o do papel masculino, assumido por Grant. A viagem a Los Angeles é relatada em cenas curtas e ágeis, nas quais desponta um traço recorrente: a alternância entre ilusionismo e desvendamento da arquitetura da ilusão. Tratase de um vaivém que afeta diversas situações: ora pode evidenciar a escassa beleza natural de uma star ("as estrelas, de dia, têm manchas e rugas"); ora desnuda os pormenores de um close-up em que o ator declara sua paixão a uma vassoura6. Em meio às reviravoltas dessa comédia ligeira, destaca-se o 
emprego de um recurso gráfico: a linha corrida de pontos, uma marca que corta a cena possibilitando a passagem à seguinte sem delongas, porém sem perda de legibilidade. O procedimento, aliado à inserção de motivos plásticos codificados por Hollywood, imprime uma feição cinematográfica ao relato.

\section{Uma viagem, duas versões}

Em dezembro de 1919, o mexicano Carlos Noriega Hope viaja a Los Angeles enviado pelo jornal El Universal, no qual assume a coluna cinematográfica. A iniciativa do periódico se inscreve em um conjunto mais vasto de ações que testemunham o avanço da cinematografia estadunidense e tendem a instituir um imaginário participativo em relação ao mundo dos sets, bem como à vida das estrelas. Nessa conjuntura, o repórter se traslada à capital do cinema com o objetivo de comunicar suas impressões a um leitor sedento de notícias sobre Hollywood'. Assinalo alguns traços das notas jornalísticas com o objetivo de examinar a relação instaurada entre elas e as ficções de tema cinematográfico escritas posteriormente por Noriega Hope. O marco inicial é dado pela visita ao estúdio de Thomas Ince:

O carro chegou às portas da Goldwdyng e timidamente fui detrás de meu amável cicerone até a sala de informações. Nunca antes em minha vida vi um espetáculo mais desolador, mais odioso e mais horrível que

de apaixonado uma vassoura" (QUIROGA, 1996, p. 449, tradução minha). No original: "en el taller, cuando los cuadros son de detalle, el escenario desaparece. Aquí el actor permanece quieto y solo mientras la máquina se va aproximando a su cara, hasta tocarla casi. Y el director le grita: -Mire usted aquí... Ella se ha ido, entiende?... Más! Eso no es melancolía!... Bueno, ahora, sí... La luz! Y mientras los focos inundan hasta enceguecerlo la cara del infeliz, él permanece mirando con aire de enamorado a una escoba". em Hollywood para alimentar o mundo com informações, fofocas e confidências sobre as estrelas. Em seu livro America at the movies, Margaret Throp estima que partiam diariamente de Hollywood 100 mil palavras, o que tornava a cidade a terceira maior fonte de informações dos Estados Unidos, depois de Washington e Nova York. Hoje em dia, as fotografias das estrelas continuam a aparecer em primeiro plano em jornais e revistas. Sua vida privada é pública, sua vida pública é publicitária, sua vida na tela é surreal, sua vida real é mítica" (MORIN, 1989, p. XV). Mais recentemente, na mesma direção, Goulart afirma: "Segundo David Marshall (2010), as estrelas são 'produções do eu' dependentes de uma cultura midiática poderosa e extremamente elaborada. A essência do fenômeno está em suas imagens que precisam ser construídas, não apenas pelos estúdios, mas também pelas entrevistas, biografias, fofocas e publicações na imprensa" (GOULART, 2012, p. 12). A atuação como repórteres do mexicano Noriega Hope e do brasileiro Olympio Guilherme deve ser compreendida nesse contexto. 
o pequeno incidente que se apresentou a meus olhos como a primeira manifestação do cinematográfico. Na sala de espera havia pelo menos três dezenas de moças [...]

- Manuel, essas moças são estrelas?

- Não são estrelas; são "figurantes" que esperam pacientemente, talvez uma hora, talvez um dia ou uma semana, que alguém utilize os seus serviços no estúdio (NORIEGA HOPE, 1921, p. 22).

A nota conclui com uma entrevista a Mabel Normand, anunciando o tom das que se seguem: o foco incidirá, a partir daí, sobre as estrelas e os cineastas de renome. O incidente do início, que se abria à possibilidade de mostrar outras facetas da vida hollywoodiana, é abandonado em benefício de uma sucessão de minibiografias marcadas pela escalada e permanência no grupo dos eleitos. Desfilam, dessa forma, Charles Chaplin, William Hart, Tony Moreno, May Allison, Douglas Fairbanks, Jack Dempsey e outros. Por fim, arrematando a viagem do repórter, uma anedota que retoma o episódio do primeiro dia em Los Angeles. Horas antes de partir, Noriega Hope visita outra vez Mabel Norman e esta lhe pede que entreviste uma moça:

- Mister Mex - diz Mabel - não vá embora sem entrevistar esta moça. Quero que escreva no México alguma coisa sobre ela [...]

- Senhor, eu queria contar-Ihe minha história porque preciso de um pouco de publicidade. Devo explicar esta frase. A publicidade nos estúdios norteamericanos mede-se milimetricamente. As atrizes consagradas "ganham" artigos e mais artigos que se distribuem em todos os jornais, mas as que começam não recebem uma linha e, como metade do sucesso depende do papel impresso... Por isso, pedem publicidade como uma esmola (NORIEGA HOPE, 1921, p. 130-31). cicerone hasta la sala de informaciones. Nunca en mi vida he visto espectáculo más desolador que el pequeño y horrible incidente que se ofreció a mis ojos como primera manifestación cinematográfica. En la sala de espera habíacuando menos tres decenas de muchachas. - Manuel, ¿son acaso estas señoritas estrellas o algo por el estilo? iPreséntamelas, por favor! Ojeda sonrió: - No, señor, son 'extras' que esperan pacientemente, quizás una hora, quizás un día o una semana, que alguien utilice sus servicios en el 'studio'". 
Ao regressar a seu país de origem, Noriega Hope escreve várias narrativas de tema cinematográfico, nas quais realiza uma série de operações a respeito da matéria-prima das crônicas. Por um lado, operações de resgate e de importação, visto que anedotas como a acima citada migram para os contos. Por outro lado, operações transformadoras que alteram pesos e proporções, modificando o estatuto do narrado. O incidente horrendo, porém nímio no discurso do repórter, se torna o núcleo de textos focados naqueles que habitam a periferia do star system: o que era a margem nas crônicas devém centro na ficção. Che Ferrati, inventor, de 1923, ocupa um lugar de destaque nesse conjunto. Trata-se de uma novela cuja estrutura é bastante próxima à da comédia de confusões, na qual comparece um motivo literário de longa tradição: o duplo ${ }^{10}$.

\section{Astros, figurantes e dublês}

Tão pobre-diabo como o argentino Guillermo Grant é o mexicano Federico Granados, jovem ator recém-chegado a Hollywood com "quinhentos dólares no bolso" e "um capital de ilusões" ao se iniciar a novela. De fato, na cronologia que marca a transição de um relato ao outro, a cifra dos pobres-diabos que anseiam levar uma vida de filme amplia-se vertiginosamente. Granados é um deles e, logo após chegar a Los Angeles, cruza com uma garota parecida com a da entrevista citada: Hazel Van Buren. A moça confessa ter confundido o mexicano

Las actrices consagradas "reciben" artículos y más artículos que se reparten a todos los periódicos americanos, pero las que empiezan no merecen una sola línea de los escribidores de cuartitas. Por eso... la solicitan ansiosamente como una limosna".

Com duas modulações fundamentais - de um lado, a fantástica, e, de outro, a realista -, o tópico do duplo se faz presente em vários relatos da época. A primeira vertente retoma em chave "tecnológica" os motivos do desejo amoroso, o ímpeto prometeico, o anseio de imortalidade e o sacrifício do original. Nessa linhagem de textos, o aparelho cinematográfico e/ou os seres fantasmáticos que ele engendra costumam vampirizar ora os originais filmados, ora o espectador enfeitiçado. El espectro (1921), El puritano (1926) e El vampiro (1927), do uruguaio Horacio Quiroga, ou o romance $X Y Z$ (1934), do peruano Clemente Palma, pertencem a esse grupo. Quanto à linha de desenvolvimento realista, a ser abordada de imediato, ela se materializa no tema do dublê cinematográfico e em formas "brandas" de imitação da/do star. Neste caso, o conflito migra para a conspurcação da identidade do dublê, cuja existência vê-se alienada e progressivamente sugada pelo astro ou estrela a substituir. Além de Che Ferrati, inventor e de Hollywood, novela da vida real, aqui examinados, cabe mencionar El hombre que se parecía a Adolfo Menjou (1929), da peruana María Wiesse, e Estrella doble (1935), do mexicano José Martínez Sotomayor. 
com um fantasmón"11 do cinema, cuja popularidade causava "estragos nos corações standard de todas as flappers" (NORIEGA HOPE, 1923, p.16, tradução minha). Hazel, é claro, pertence à categoria. O incidente tem por função pôr em cena um indício do que virá, pois Granados se assemelha deveras a um astro que se tornará um fantasmón ao morrer em plena rodagem e ao qual ele substituirá, primeiro nessa fita inacabada e depois em outra e em outra mais, até transformar-se num dublê em caráter permanente. Mas o episódio também serve para dar início a um jogo de sedução no qual as personagens assumem atitudes que imitam e duplicam as da tela, favorecendo uma profusa circulação de clichês: de um lado, o latin lover (Granados); de outro, a girl bonita e infinitamente ignorante em relação a tudo, muito especialmente, em relação à South America. A terceira personagem importante dessa galeria de tipos é Ferrati, o argentino que dá título à narrativa: figurante no passado, inventor de um set em miniatura que faz poupar cem mil dólares à Superb Picture depois, diretor artístico do estúdio na atualidade. Artífice de truques geradores de ilusão e de dividendos, o argentino desempenhará um papel-chave na trama.

Quando Granados conhece Ferrati, este está envolvido em uma nova invenção: uma pomada, que pode ser modelada sobre os rostos; uma segunda pele, capaz de suplantar a original. A morte inesperada do astro, ao qual o mexicano se assemelha fisicamente, provê a ocasião de experimentar o novo truque. Num primeiro momento, a maquiagem parece ter vindo para satisfazer as expectativas de todos: do diretor do filme interrompido, que anseia concluíIo; dos empresários e de Ferrati, ávidos pelo lucro; das fãs, desejosas de ver mais uma vez seu astro; de Granados, ansioso por abandonar a condição de figurante anônimo e que enxerga o papel como uma chance de demonstrar, por fim, sua destreza interpretativa. Entretanto, a situação se revela menos simples do que parecia à primeira vista. De um lado, a substituição convincente de Le Goffic prova o valor de Granados como intérprete; de outro, o deflaciona 
sob o peso que possui a imagem pública da figura suplantada. De um lado, a substituição demonstra que a celebridade é um produto fabricado e fabricável; mas mostra, ao mesmo tempo, que o valor de mercado difere segundo o tipo de mercadoria. Existem as mercadorias de luxo (astros e estrelas) e as mercadorias ordinárias (figurantes e dublês). Existem os originais e as cópias. Ninguém é inerentemente isto ou aquilo. A posição no tabuleiro decorre de múltiplos fatores e é essencialmente móvel: a estrela de hoje pode devir o figurante de amanhã; o desconhecido pode ser beneficiado por um lance de sorte. O dublê, todavia, parece condenado a replicar indefinidamente o fantasma que imita. Embora vestir a pele de uma personagem fictícia ou dessa produção do eu não menos inventada que é o astro sejam operações equiparáveis, a lógica de um modelo que se fundamenta no caráter intercambiável de suas peças e, simultaneamente, em sua hipotética singularidade proíbe o reconhecimento do dublê, sob pena de depreciação da celebridade. As peripécias de Granados servem para patentear os paradoxos desse sistema, cujos tentáculos se alastram muito além do espaçotempo da rodagem. Com efeito, outro dos aspectos explorados pela narrativa é a imbricação estreita entre vida pública e vida privada, na qual se apoia o star system, fenômeno que comporta a progressiva confiscação do sujeito pela máscara assumida nas mais diversas esferas, obrigando o mexicano a interpretar sua personagem dentro e fora dos sets. Se, como sustenta Morin (1989, p. XV) a propósito das estrelas, "sua vida privada é pública, sua vida pública é publicitária, sua vida na tela é surreal, sua vida real é mítica", a vida de Granados ilustra à perfeição essa premissa.

\section{Hollywood, novela da vida real}

Em agosto de 1927, é o paulistano Olympio Guilherme quem chega a Los Angeles. Embora Guilherme já colaborasse com a imprensa e viesse a escrever de lá para a Cinearte, a viagem decorre da premiação num concurso promovido pela Fox, que envolveu três países: Chile, Argentina e Brasil (GOULART, 2012). O processo que se delineava quando o mexicano publicara suas notas ganha 
proporções continentais um quinquênio posterior. Daí a reaparição de vários dos tópicos já examinados. A corte de figurantes se amplia, sendo constituída, de início, por Lucio Aranha - protagonista e alter ego do próprio Guilherme -, Vicentini - "decano dos extras brasileiros" -, o argentino Gutiérrez e o francoegípcio Irarah. O ambiente de instabilidade laboral e de precariedade material se acentua. O fenômeno do mimetismo e sua manifestação sob a forma do dublê proliferam ad nauseam: o cachorro da república na qual moram os aspirantes a atores é dublê de Rin-Tin-Tin; Vera, a coprotagonista feminina do enredo, é dublê de Greta Garbo; Chaplin e Talmadge possuem seus dublês.

Se Quiroga lançava mão da linha corrida de pontos como sucedâneo do corte/montagem invisível, Guilherme importa no prefácio um vocabulário frequente na produção escrita do período: de um lado, opta pela expressão Fade in para intitular as palavras preliminares; de outro, a primeira frase sugere uma correspondência entre o ingresso do leitor no texto e do espectador na sala: "Este livro é um retrato. Talvez haja quem duvide. É por isso mesmo, esperando discordâncias de opiniões, que, nesta salinha de espera, onde o leitor tira o capote, eu venho informá-lo de que este livro é um retrato" (GUILHERME, 1932, p. 7). No entanto, para além da analogia proposta, o peso recai sobretudo na "veracidade" do "retrato" oferecido ao leitor. Contra a "Hollywood endomingada e risonha" à qual o habituaram as revistas, a imagem "sem retoques": "Essa Hollywood ditosa não a conheço eu, mísero fotógrafo [...] a Hollywood que posou diante da minha caixa quadrada..." (GUILHERME, 1932, p. 10). De fato, não era a primeira vez que o "fotógrafo" propunha um misto de testemunho pessoal e de registro histórico. Três anos antes de dar a conhecer esse retrato escrito, Guilherme produziu, dirigiu e protagonizou uma fita semiautobiográfica sobre as agruras de um ator latino em Hollywood: Fome (1929). Tudo indica que a novela de 1932 deva ser lida em paralelo com essa versão cinematográfica prévia12. 
O relato de Guilherme se inicia com uma cena rotineira na vida do protagonista e de muitos outros: a espera. Como se afirma pouco depois, em Hollywood, "às seis horas recrudesce o serviço dos telefones do Central Casting", pois os estúdios fecham o expediente e "quinze mil extras" ficam ouvindo "vozinhas femininas", que "cortam como lancetas" a súplica de um dia de trabalho, dizendo: "nothing". Também às seis horas, "sendo possível, Hollywood senta-se à mesa e come". Não o jantar farto; "a jantinha feita em casa, requentada, às vezes mesmo insuficiente" (GUILHERME, 1932, p. 15). É esse clima de privações que o leitor é convidado a olhar de perto; são as peripécias que visam driblar esse destino, via de regra imodificável, que ele acompanha por trezentas páginas. Na representação desse universo, destaca-se um motivo que molda a realidade hollywoodiana: o burburinho que se torna logo notícia. Essa Hollywood maledicente também entra em atividade intensa às seis:

É a hora predileta do escândalo, do cochicho segredado com as mãos espalmadas sobre a boca. Repórteres vindos dos quatro cantos da terra ficam de atalaia [...] Uma notícia inocente contada na esquina de Vine Street $[\ldots]$ quando chega a Highland, sete quarteirões distante do seu ponto de origem, é escândalo grosso, escândalo de primeira página. No dia seguinte, como dinamite, explode ruidosamente pelo mundo inteiro, na consagração da letra de forma (GUILHERME, 1932, p. 14-15).

A letra de forma havia conduzido Noriega Hope a Los Angeles em 1919, quando a malha publicitária indissociável do studio system acelerava sua expansão; para a letra de forma, Granados era obrigado a desempenhar seu papel fora da tela. Uma década mais tarde, a dinâmica de um modelo inconcebível sem esse produto secundário (apesar de principalíssimo) que constitui a vida privada (embora pública e publicitária) de celebridades convoca repórteres dos quatro cantos do planeta. Essa trama paralela, arquitetada em letra de forma, comporta uma dupla vida ou representação generalizadas. Seja porque se aspira a sobressair da massa anônima de figurantes, seja porque se deve alimentar a fama preservando uma determinada aparência: aqueles que existem ou são candidatos a fazê-lo precisam existir tanto no celuloide quanto na imprensa. 
Duas publicações fictícias trazem para dentro do relato o universo dos pasquins: A Gralha e O Monóculo. De alguma forma, a sorte de Lucio Aranha se dirime entre uma fofoca publicada em A Gralha e uma entrevista concedida ao Monóculo - entre uma e outra, o extra galga à condição de tipo e se torna um gigolô.

\section{Sistematização de uma linha de montagem}

A novela começa com uma ligação que parece instaurar uma perspectiva de mudança em meio ao clima de desânimo. Convocado para uma prova, Lucio se dirige ao estúdio - e fica horas trajado de palhaço para fazer um teste fotográfico. O fiasco introduz no enredo a coprotagonista feminina. Num primeiro momento, Lucio acredita estar diante de Greta Garbo; dias depois, reencontra Vera, apresentada agora com todas as letras como dublê. O diálogo entre ambos abre espaço a uma série de considerações sobre as incumbências desse tipo, substitutivo do original:

\footnotetext{
O studio empregava a dublê para os long-shots e os preparativos dos efeitos de luz. Trajando vestidos idênticos, Vera ficava no lugar em que a estrela ia representar, enquanto os eletricistas e cameramen compunham a cena [...] Quando tudo estivesse pronto, Greta Garbo, em pessoa, ocupava o mesmo sítio onde momentos antes, Vera posara (GUILHERME, 1932, p. 53).
}

Pouco depois, a rodagem de uma sequência com mil e duzentos extras volta a reunir Vera e Lucio. A situação propicia a emergência de um tópico já comentado; sua retomada dá-se segundo a lógica da intensificação e do rebaixamento. Sem vestígios do encantamento que pautara a descrição do repórter mexicano, o set, aqui, assemelha-se a um "hangar". O imaginário da terra de maravilhas cede lugar ao pandemônio fabril:

A desordem que reina dentro desses barracões é indescritível. Por toda parte se vêem refletores e cabos elétricos [...] O calor das luzes sufoca; ouve-se um bater contínuo de martelos automáticos; o olfato se corrompe com o cheiro nauseabundo das tintas (GUILHERME, 1932, p. 60-1). 
O mapeamento dessa lógica de produção em série completa-se, por fim, com considerações sobre a função dos tipos:

\footnotetext{
Os diretores não querem atores, querem tipos [...] A formação de tipos foi o primeiro passo para a estandarização do cinema [...] O tipo não é um simples extra. No plano cinemático, o extra é a "atmosfera" e está, quase sempre, out of focus. O tipo é a figura intermediária [...] Economicamente, a maior vantagem do tipo é a de não precisar de muitos metros de filme que the definam a caracterização - porque o público já o conhece de sobra (GUILHERME, 1932, p. 121-2).
}

O enredo dramatizará a seguir a passagem de Lucio da condição de extra à condição de tipo. Mas a interpretação do gigolô que quer encarnar na tela principia pela adoção da máscara ao atravessar a porta da república. A contaminação cinema/vida, já apontada em relação a Federico Granados, apresenta-se agora invertendo a lógica causal e a sequência temporal. Trata-se de um teatro a céu aberto que inclui quase todos. Transformada em uma representação contínua, de fronteiras fluidas, sem início nem fim, a espetacularização da vida é a realidade última de Hollywood.

\section{Fade out}

O livro de Guilherme busca traçar um retrato pormenorizado e "sem retoques" da "vida real" em Hollywood, mas é também uma novela sentimental imersa nesse mundo. De um lado, a presença dessa trama atesta o caráter inescapável de convenções que não são uma invenção hollywoodiana, embora tenham encontrado aí um solo propício: a primeira aproximação fortuita e marcante, o segredo em torno do passado da mulher amada, o amor puro e casto a despeito da impureza do ambiente - esses são, dentre outros, motivos folhetinescos atualizados pelo par Lucio/Vera. De outro lado, evidencia-se um esforço em des-romantizar parcialmente esses leitmotiv, integrando-os ao clima de desalento que tinge as experiências narradas. Ora, se o desmascaramento das regras do jogo, nos sets e fora deles, conduz o enredo precisamente a uma solução dos conflitos no plano sentimental, o último lance da história torce 
mais uma vez o rumo. Com efeito, tomada a decisão de abandonar os Estados Unidos e de começar uma vida a dois no Brasil, surge a oportunidade que Vera aguardou em vão durante anos: assumir um papel como intérprete autônoma e não mais como dublê. O dilema resolve-se em favor da fábrica de sonhos e Lucio Aranha parte sozinho. O leitor assiste à cena tendo a impressão de que, a despeito do ímpeto anti-hollywoodiano, Guilherme rende tributo ao que renega:

\footnotetext{
O trem deu um arranco, as molas perras dos carros rangeram; os freios de ar comprimido silvaram, como um bando de moleques vaiando; e, resfolegando com seu pulmão de ferro, o trem deslizou, lentamente, envolvendo a estação em rolos pardos de fumaça... FADE OUT (GUILHERME, 1932, p. 315).
}

Não somente a imagem se esfumaça, fechando o fade in/fade out que marca os limiares do livro à maneira de um filme; seu conteúdo remete a um dos fetiches cinematográficos por antonomásia: a estação, as nuvens de vapor que envolvem o trem, o encontro, o reencontro, a despedida ou a partida solitária. Inclusive quando se trata de um unhuppy end, o imaginário hollywoodiano ganha a partida. 


\section{Referências}

BOY. "Una aventura de amor". In: BONGERS, W.; TORREALBA, M.; VERGARA, X. Archivos iletrados. Escritos sobre cine en Chile: 1908-1940. Santiago: Cuarto Propio, 2011.

GOULART, I. "Estrelismo à brasileira: perspectivas de uma negociação simbólica, estética e cultural entre Hollywood e o Brasil". Rumores, v. 1, n. 9, 2011. Disponível em: www.usp.br/rumores. Acesso em: 20 fev. 2014.

. "A fina flor da formosura: o concurso de beleza fotogênica da Fox Film (1926-7) e o discurso social sobre os corpos modernos". In: Jornada discente PPGMPA-USP, 2012, São Paulo. Anais eletrônicos. São Paulo: ECA/USP, 2012. Disponível em: www.pos.eca.usp.br/.../artigo_jd_212. Acesso em: 20 fev. 2014. GUILHERME, O. Hollywood, novela da vida real. São Paulo: Nacional, 1932.

MORIN, E. As estrelas. Mito e sedução no cinema (1969). Rio de Janeiro: José Olympio, 1989.

NORIEGA HOPE, C. "Che Ferrati, inventor". In: Las experiencias de Miss Patsy y otros cuentos. México: Talleres de El Universal Ilustrado, 1923.

QUIROGA, H. "Miss Dorothy Phillips, mi esposa". In: Todos los cuentos. México: ALLCA XX, 1996.

XAVIER, I. O discurso cinematográfico: a opacidade e a transparência. Rio de Janeiro: Paz e Terra, 1984. 